Bringing installation art to reconnaissance to share values and generate action.

Andrew Townsend and Pat Thomson, with the "Get Wet" team

School of Education, The University of Nottingham

School of Education, University of Nottingham, UK.

andrew.townsend@nottingham.ac.uk 


\section{Bringing installation art to reconnaissance to share values and generate action}

The English education system has recently seen something of a revival of enthusiasm for the use of research to both develop, and gather evidence about the effectiveness of, educational practices. These initiatives often present action research as a model of individual problem solving which, we argue, communicates a limited conception of action research. In this paper we propose an alternative to this 'problem solving' conception of action research which acknowledges the complex, messy nature of action research through the use of art installations. Specifically we present the reconnaissance phase of a project which brought together a partnership comprising a water heritage museum, university staff, teachers and artists. A pedagogical adaptation of contemporary installation art theory and practice fostered the exploration of individual and collective understandings of water, and also established a shared approach to curriculum development and ownership of the project among all participants. We propose that this creative practice enhanced and changed the process of reconnaissance; it allowed the group to establish and share commitments to the value of water conservation and generated a wide range of options for our action research.

Keywords: arts installations; reconnaissance; conservation; environmental education; messy methods; complexity theory.

\section{Introduction: challenging an instrumental view of action research}

There is currently a prevailing instrumental view of action research in the English education system. In this paper we show how the use of arts installations in a water education project challenged this view by enabling a group of action researchers to develop shared values and establish a common purpose for their work. This use of arts installations is presented as a way to initiate action research with groups of people who have differing roles, responsibilities and interests, in a way which promotes dialogue, mutual understanding and shared values. As Davis and Sumara (2005) put it, this is a means by which the interests of autonomous agents can be brought together to form grander collective possibilities. The use of arts installations is, we suggest, a way to acknowledge and work with the complexity of human 
relations (Davis \& Sumara, 2005; Mayer, 2003; Phelps \& Hase, 2002) in a manner which embraces this “"messy area' as a vital element for seeing, disrupting, analysing, learning, knowing and changing" (Cook, 2009: 277). Our approach is not only more creative but also more faithful to the participatory, empowering, community building traditions of action research.

At present research is being promoted for and to teachers in English schools through a range of different initiatives, including the promotion of forms of evidence-based practices in which research is seen as a means to identify and analyse phenomena which then acts as a basis for changing practice (Cordingley \& Groll, 2014). There have also been changes to the ways in which schools are organised in England, which has had implications for how teachers and school leaders conceive of the relationships between research and practice. In particular this has arisen through the designation of certain schools as Teaching Schools whose remit (Coldron, Crawford, Jones \& Simkins, 2014) is in part to undertake a programme of research and development (for examples of how some of these alliances have operated see: NCTL, 2014). This has promoted a particular instrumental view of how educational practices relate to research (Godfrey, 2014). Other developments, most notably ResearchEd events, have also promoted causal "what works" links between research and practice in education, initially through conferences and seminars but also through social media (see: http://www.workingoutwhatworks.com/).

In each of these differing initiatives research is seen a transparent problem-solving activity, with actions merely the consequences of a better understanding of the 'problem'. Solutions are then able to be transferred and applied generally. This is a model of research that separates action and research, seeing them as entirely different activities. Research leads to evidence which leads to action. This conception of action research is a limited one (Hadfield \& Bennett, 1995) and in contradiction to the participatory aspirations of action 
research (Winter, 1998) in that the staged instrumental approach is adopted at the cost of more principled efforts geared towards providing a voice for people over a process of change. Considerable concern has been expressed about this kind of instrumentalisation of action research which stems in part from the ways in which action research has been put to work on problems that meet the needs of systems, and in part from 'scientising' or 'methodologising' process models of action research (Cain \& Harris, 2013; Carr \& Kemmis, 1986; Grundy, 1987; Kemmis, 2010; Noffke, 2009; Rué, 2006).

In this paper we present a different approach, the early, reconnaissance phases of the 'Get Wet' project, a project that brought together the education officer from a water heritage museum, four teachers from four different schools, five artists and four university staff members, two of whom are the authors of this article, to develop an interdisciplinary water curriculum. In this project our own use of action research was geared towards more transformational goals (Wood, 2012) than simply instrumental conceptions of research. The approach we adopted was one which saw a 'process' as an emergent feature of complex and messy shared work, rather than as something which should be pre-determined (Ahmadian and Tavakoli 2011; Cook, 2009). The project was specifically concerned with water education, and our aspirations were that through a process of reflection and dialogue, stimulated by arts installations (Reiss, 1999), a group of partners could develop collaborative relationships with each other, establish shared values for a common task, and work together in ways which were geared more towards the aim of realising human potential than in solving specific problems:

I do not see action research as about problem-identification or problem-solving, but as about realising human potential.....It is our responsibility to realise our capacities for creative living for one another's benefit (McNiff, 2013: 35). 
We began the project thinking about our shared understandings, beliefs, hopes and aspirations for the project. This was accomplished through the use of 'installations' a pedagogical strategy based on contemporary art practice. We argue that 'the installation' afforded open-ended ways to consider what we collectively wanted to do. In reflecting on this process, we offer in this paper a reconsideration, and reimagining, of the early stages of action research, drawing on the concept of reconnaissance, which challenges the instrumental models of action research presently being promoted in the English education system. The origins and characteristics of reconnaissance are signposted in the next section.

\section{Revisiting reconnaissance, questioning the process model of action research}

Discussions of reconnaissance are relatively rare in the action research literature and where they do occur they often relate reconnaissance to reflection (Mason, 2005; Robertson, 2000; Webb \& Scoular, 2011). The concept of reconnaissance was first identified by Lewin who, in making an argument for the need for a form of social research concerned more with understanding and changing 'the specific character of situations' (Lewin, 1946) suggested that the early stages of action research should include a stage of 'fact finding' which he termed 'reconnaissance'.

It should be noted that the development of a general plan presupposes "fact-finding."... Fact-finding is necessary to structure the goal, its relation to the total setting and the path and means which may lead to the goal. On the basis of this fact-finding the goal is usually somewhat altered in light of the findings concerning the means available. (Lewin, 1947: 147)

The purpose of reconnaissance is that, at the outset, action researchers interrogate their 'problem' or 'question', explore what they usually take for granted and generate additional information that they feel they need in order to plan research/action (for examples 
of this 'fact finding' interpretation of reconnaissance see: Bana, 2010; Elsey \& Lathlean, 2006; Lewin, 1946; Tragoulia \& Strogilos, 2013).

Questions have been raised about whether Lewin conceived of reconnaissance as part of a staged process of action research (Adleman, 1993). An alternative interpretation is that action research does not refer to a particular process or methodology, but 'is embedded into the way that a whole organisation or organisational system works' (Burns, 2007: 18). In this model reconnaissance becomes an activity which runs alongside action research where people whose work intersects come together to reflect on and discuss the effects of any changes they have tried to make and to share any insights they think they have gleaned. Reconnaissance can, therefore, be seen as both a form of fact finding to inform and judge the effects of actions, and also as a means of developing collaborative communities of action researchers.

Our own use of reconnaissance was intended to combine these features of fact finding and community formation. One of the distinguishing features of action research is that research is not done 'on' people but is a collective activity in which "the focus of the work is to find ways of developing creative and healthy opportunities for all, for learning and growth" (McNiff, 2013: 31). Our intention was, in part, to adopt an approach which challenged a linear instrumental conception of action research and in part to establish a form of reconnaissance which encouraged both reflection and dialogue. We achieved this through the use of arts installations, with their associated ontological and epistemological assumptions, as a 'provocation'.

\section{Art installations as provocation}

From 2003 - 2011 the English government funded artists to work in schools. The goal was to bring creative strategies to teaching/learning in order to encourage new processes for 
exploring a topic, acquiring new knowledge and know-how, and communicating the learning. The programme supported, across the country, a cohort of artists particularly interested in education, and they adapted processes from their arts practices to become what have now been called 'signature creative pedagogies' (Thomson, Hall, Jones, \& Sefton-Green, 2012). One of these is 'the provocation'.

The provocation is common to creative practitioners from theatre, performance and contemporary visual and live art practices. In essence it consists of beginning a learning 'project' with an unexpected event or object to stimulate imagination, open ended thinking, discussion and play. Provocations can range from a volcano appearing in the grounds of a school overnight, Shakespeare wandering the school corridors greeting students as they arrive in the morning, a storyteller singing outside the classroom to the creation of entire classroom environments which students are invited to explore and also to interact with and with each other (see http://www.signaturepedagogies.org.uk/common-approaches/making-anoccasion/provocation).

The provocation used in the Get Wet project was an adaptation of contemporary visual arts installation practice. The five artists engaged in the Get Wet project all had long histories with Creative Partnerships and brought a well-honed strategy to our need to establish, at the outset, a shared conversation, values and approach across the four schools and university team.

In contemporary visual arts practice the installation refers to an art work - perhaps a series of objects or an environment - which is physically entered by a viewer who 'animates' it; the work is incomplete without the viewer it addresses. An installation generally aims to 
elicit a direct embodied response from a viewer who is immersed in it as an experience. It can thus be differentiated from more conventional paintings and sculptures which a viewer only ‘sees' (Reiss, 1999). Art historian Claire Bishop (2005) identifies four different types of viewers and installations. One of these is 'activated spectatorship', a type of installation which aims to engage viewers in political conversations and encourage them to take political action. It is this latter modality of installation which inspired the Get Wet provocation.

A further and key aspect of the Get Wet provocation was also drawn from contemporary art practice, which is grounded in philosophical traditions of not knowing. Not knowing is understood as ontological, as a condition of life. From this perspective, artistic practices do not seek to rectify this lack of knowledge and know-how. Rather, their purpose is to explore the state of not knowing, perhaps to disrupt what is understood as 'known'. The world, an event, a phenomenon is always understood to be open to questioning, wondering and engagements with 'others' (Jones, 2013). This use of art, therefore, provides a practical means "for seeing, disrupting, analysing, learning, knowing and changing" (Cook, 2009: 277). The Get Wet artists thus expected that their provocative installation would not only provoke dialogue and political action, but it would also support unknowing - and an openended exploration of what was important, why and what was to be done.

\section{Educating for Water Literacy, the Get Wet project}

The hub for the 'Get Wet' project was a heritage museum called Papplewick Pumping Station

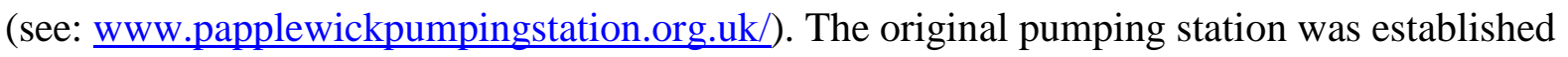
1881 - 84 to bring clean water to industrial areas of Nottingham where water borne diseases, especially cholera, were commonplace. Papplewick thus changed the health of the local 
population. Papplewick Pumping Station is an especially significant site as it has two beam pumping engines, believed to be the last manufactured by James Watt and Co., the company founded in 1779 by the pioneering engineer (for more on Watt's role in developing the steam engine see: Hunt, 2010). The original pumping station is now a museum with a mission to educate about water use and conservation, through the Water Education Trust (WET). The Get Wet project was formed alongside this Water Education Trust to develop an innovative, interdisciplinary approach to learning about water which:

- builds on students' existing knowledge, curiosities and interests

- brings teachers together across subjects and sectors

- works from and with the professional pedagogical capacities of teachers

- establishes a curriculum development partnership between the third sector, higher education and schools.

To do this we brought together the project team noted above. As is common in action research projects in education this team included university researchers and teachers from affiliated schools. Because this work was conducted in partnership with Papplewick Pumping Station, and made explicit use of art to inform the process of action research, and also as a component of the resulting pedagogical processes, the team also included a group of artists and the educational officer from Papplewick. This was not intended to be a project in which academics imparted knowledge to teachers, and other project members, with the intention that they then shift or adapt their practices in accordance with these new instructions; instead all members of the team were seen as active researchers and producers of knowledge, whose identities and their ways of relating to this project could evolve through a period of dialogue and collaboration (McNiff, 2012). In keeping with this aim the aspiration was to use arts installations to stimulate reflection and dialogue among the research team. Specifically the 
project team included:

- Four members of staff from the University of Nottingham, two action researchers and two teacher educators,

- a representative of the Water Education Trust based at Papplewick Pumping Station,

- five artists who: supported the creative approaches to reconnaissance; informed the development of creative approaches to teaching about water use and documented the progress of the project,

- $\quad$ staff from four schools, of which two were secondary schools (i.e. with pupils aged 11-18) and two primary (i.e. with pupils aged 4-11).

At the heart of this initiative was a conviction that environmental education is best achieved through a process driven by inquisitiveness and curiosity (Nicol, 2013), and not through generating a sense of guilt, which communicates a view of action research as a deficit model, and which has been found to be counterproductive by stifling, rather than promoting, action (Kollmuss \& Agyeman, 2002). It was instead concerned with challenging preconceptions and encouraging new perspectives on water, in short with a process of 'problematisation'. Adopting this approach provided a means through which the perceptions of water and its use and management could be re-examined.

The provocation and its attendant problematisation were intended to challenge preconceptions of water as a taken-for-granted resource. It was also intended to provide an informed basis upon which to understand the need for water management and to appreciate the contribution of Papplewick Pumping Station in providing clean water. The starting point for this project was, therefore, neither a certainty about a problem nor a fixed conviction about a 'solution'. It was, rather, a desire to make explicit and challenge preconceptions, to problematise the aims of the Get Wet project and to form a consensus of values across the 
team which would underpin our action research. In that respect this was not research which was intended to be neutral or 'value free' (McNiff, 2012); instead the particular values which underpinned this work were intended to emerge from the formation of shared understanding established through a period of reconnaissance which we re-imagined as arts installations.

\section{Reimagining reconnaissance: developing shared values through arts installations}

The Get Wet project was designed as a multi-sited action research project, with the intention that each of the teachers would work with university representatives and artists to develop new pedagogical approaches for teaching about water use and management which both embraced the creative aspirations of the project and made use of Papplewick Pumping Station as a resource.

Two stages of the 'arts installation' reconnaissance were held at the start of the project. The first of these was prior to the schools joining the project and was attended by the university personnel, the artists and the representative of the Water Education Trust; this was then repeated with teachers from the participating schools joining in. The first arts installation was held over the course of a day at the university, the second took place at an arts centre close to the pumping station and included a visit to the site.

At these events members of the project were asked to identify, and bring with them, an object which was associated with a story and which for them symbolised water and its attendant issues/potential/histories. The session started with each person sharing the objects and telling the stories which arose from their initial reflections. But this 'problematising' reconnaissance did not stop at merely reflection, nor did it simply characterise the focus of this work as being a deficit 'problem' to be solved. Following this initial step the project team were given a space and a range of resources and asked to use these materials to produce 
items which they felt represented the issues that they would want to address through their action research. Some of these are shown in Figure 1.

\section{INSERT FIGURE 1 ABOUT HERE}

Each member of the team then shared the items they had produced, explaining to the others what they had made and what it represented about their hopes and aspirations for the Get Wet project. These objects were commented on and discussed by the team as they were shared. This was an active use of art (Reiss, 1999) in which the project participants were encouraged to reflect on their interests in water, to use materials provided to produce a piece of art, and then to share and discuss what they individually, and the group collectively had produced.

Whilst the sharing of the two objects - the one brought to the seminar and the one produced from the materials provided - did stimulate more reflection of the kind commonly associated with reconnaissance (Robertson, 2000; Webb \& Scoular, 2011), the dialogue which followed this sharing allowed for a deeper examination of the values and interests of members of the project. Being asked to produce a piece of art to share provoked a reflection on the purposes and views of individuals, but sharing them challenged group members to consider one another's values and purposes, and to start to build some coherent shared agenda. An example of this can be seen in Figure 2, which shows a 'science' theme. 
Following the stage in which group members shared the objects they had produced using the arts materials, the group then collectively started to identify and cluster these objects under some shared themes. The production and thematising of these items provided a basis on which we could consider the meaning of 'water literacy'. This enabled us to move from sharing individual values and beliefs, to developing collective values and beliefs which they would then seek to enact through this project. From these two arts installations a total of five themes emerged, of which the science theme shown in Figure 2 was one. These themes were recorded and notes taken of the nature of the installation in question and of the discussion associated with it. This allowed the individual values of each member of the project to be represented through art and then discussed subsequently. Each of the five themes are listed below, with a brief description of the issues they raised. The first, which concerns the personal stories of project members, is described in a little more detail as it, more than any other theme, raises issues about the contribution that this arts installation model of reconnaissance made to establishing the shared values which the project members wanted to address in this work.

(1) Personal stories. This theme drew together the personal stories of the project members. Each of these was represented through an object created during the arts installation reconnaissance and when shared linked the stories of personal experience to the values that participants felt should underpin and should be enacted in this action research. An additional arts installation in this theme was a paddling pool filled with corks and vessels. People would then either write or create an object to represent their stories which were then floated on the corks or vessels.

These personal stories raised a range of issues. For example one of the team members spoke about the 'power of water' based around their experience of once feeling as 
though they were being pulled out to sea by a strong tide. Another project member emphasised the potential for individuals to exercise their agency in the protection of water as a natural resource, noting the following personal story 'My Dad stops a chemical company being built on a river....the potential of pollution affecting the livelihood of people, the fish and environment are devastating. I am proud of him'.

(2) Spiritual/ Philosophical. The second theme raised through this process concerned the spiritual and philosophical aspects of water. The arts installation for this theme drew together a range of objects, including a wall of plastic bottles (representing stained glass) and a range of religious symbols including a fish, a vessel and a tree. Under this theme project members raised issues about the spiritual treatment of water and its place in religion and philosophy. This included religious representations of water, such as in stained glass windows in churches, and raised questions about why this was significant. From this some paradoxes were identified, for example the use of water as a means to purify or as a cause of death. It also raised spiritual ideas like 'being in tune with nature'.

(3) Local. The arts installation for this theme brought together a range of items including a 'journey stick', a large old-fashioned clock, a battered kettle, a map and an old lantern. This topic was linked to local water needs and also to local history (the oldfashioned clock represented history). The journey stick is a teaching method for telling the story of a journey; in this case it was used as a metaphorical journey through history which related the need for Papplewick pumping station and told the story of its construction in order to provide a supply of clean water which had such a dramatic affect on the health of local people. This in turn raised questions about how young people can be given the chance to appreciate heritage archives, and to appreciate their own local history. 
(4) Global. The global use and management theme contrasted with the previous theme on more local issues. The arts installation for this theme made use of a projector through which images of the world as a blue planet were shown. The issues raised under this theme included concerns of unequal distribution of 'clean' water, of the diseases which result from inability to access clean water in some parts of the world and the associated problems of water management. This theme also raised questions about how best to communicate these issues, specifically questioning whether 'doom laden' messages are helpful. This concern about global water management was linked to the following theme concerning geographical/political issues.

(5) Geographical/political. The installation for this topic included a bucket and umbrella. This raised issues of national security, of international politics and water scarcity as a possible cause of conflict. It also raised issues about water as a source of power and influence.

(6) Scientific. The arts installation for this theme is shown in Figure 2. This consisted of a range of scientific equipment including Petri dishes, test tubes, filtering equipment and paper towels. The Petri dishes had ice cubes and liquid water in them and this installation raised issues about the unique properties of water, including the significance of the climate of the earth being at the 'triple point' of water at which water can exists in all three states. It also raised the topic of the water cycle and emphasised the reasons for water being the basis for life.

This approach to reconnaissance enabled participating members to reflect on their personal values and explore how they could be addressed through collaborative action research. But as these values were represented in objects, and then explained to others, this allowed the group to reveal their beliefs and hopes for the water education project. In the 'adult' version, we had linked the individual themes and the associated discussions back to a 
core theme about the requirements of a curriculum for education about water use and management. This is shown in Figure 3. However, we didn't want to impose this idea ready made on the students, which would have reproduced the imposition of curriculum as is frequently the case in schools.

\section{INSERT FIGURE 3 ABOUT HERE}

The arts installation provided an unexpected experience for the group which disrupted what is taken for granted or 'known' (Jones, 2013) by challenging their attitudes and beliefs towards water education. The installation stimulated reflection on individual purposes, which provided a basis through which shared values could be identified and collective purposes established through sharing, dialogue and processing the products of the arts installation. It was a way to acknowledge the diversity of personal experiences, views, values and beliefs, and bring some form of order out of this complexity (Davis \& Sumara, 2005; Mayer, 2003; Phelps \& Hase, 2002) in ways which acknowledged and respected personal viewpoints and allowed form to grown from 'mess' (Cook, 2009: 277). The 'provocation' (Thomson, Hall, Jones \& Sefton Green, 2012) approach to reconnaissance, therefore, not only incorporated reflection, but also provided a stimulus for project members which resulted in sharing and dialogue and the creation of new and shared values upon which the following stages of the project could evolve. One teacher described this opening activity as follows.

The very first thing we did was... we started to discuss about water and we said 'OK we are going to start a topic about water and, basically, what do you know and what do you want to know?' So we left it very open. The children then had post-it notes and they wrote down questions about water and we just left it very open. We then brought them 
altogether as a class and we discussed it altogether... and we grouped these questions and comments into... [different] areas (Primary teacher)

These questions, which had been generated in each school, became the basis for the teachers' projects. This was a process which was supported by the differing partners, for example some artists visited schools to provide a stimulus for children to reflect and think back about their interests in and current understanding of water. One teacher described this process as follows:

We started off with [two artists] coming along and doing an inspiration session with a lot of stills of water from every possible sphere of life... [and this led to] the questions... and as such a completely open project. And [the children] seemed focussed on the 'magic of water' ... what water was, what it did, how come it's here, what water actually is, how water got to us, the power of water, and so we based a series of lessons on that... The fascination [the children experienced] with the simplest things with water was amazing and the 'wow factor'... was really great to see. (Primary teacher)

Each school's project incorporated visits to Papplewick Pumping Station and included support from the university representatives and artists in devising and then implementing their plans. Student learning on this visit was underpinned through different kinds of activities in which art played differing roles; this included producing models relevant to the pumping station and to actors taking on the roles of key historical figures.

We went to Papplewick and... there is such a richness at Papplewick and there is so much you can do... and it is like a temple to water, they explored it and drew, they [made models] their 'wow factor' again at the moving machinery when it was in full steam, and they couldn't believe that there was water coming up from underground and to make those links in their minds was just incredible. Peter was amazing at being James Watt... he dressed up and he... re-enacted being James Watt and he was being James Watt in the place where James Watt machinery was being used. (Primary teacher) 
The arts installations were the initial stimulus for the establishment of shared values and for the development of individual school based projects, each of which entailed a variety of partnerships among teachers, artists, university researchers and the education office from the Water Education Trust. The specific detail of each project which followed this arts installation reconnaissance varied and whilst the aim of this article is to not to provide an account of each of these we have provided a brief narrative about one project in Figure 4, by way of illustration.

\section{INSERT FIGURE 4 ABOUT HERE}

It is our belief that this model of reconnaissance, making use of arts installation as a shared activity between a group of action researchers committed to a common cause, provides a more social and more creative alternative to some of the limited, instrumental, problem-solving models of action research which, as documented earlier in the article, are presently being promoted as appropriate means for teachers to research their practices (Tragoulia \& Strogilos, 2013). Problem solving models of action research have been a particular cause for concern for action researchers who, as a means of counteracting these approaches, have raised questions of them, such as: 'who has asked to address this problem?' And: 'for whom is this a problem and why?' By beginning with an open ended puzzle, the subject to be addressed through action research is problematised through the asking of questions; it is made problematic through critical and reflexive conversations and interactions 
rather than starting out as a predetermined issue to be fixed. The main emphasis in this use of arts installations was in providing a mechanism by which a group of disparate project members could develop a better understanding of each other, a sense of shared values and, from that, a common purpose for their work, albeit with differing views on how that purpose could be achieved. Throughout this process we have identified three main contributions that the arts installations made to this reconnaissance:

(1) Arts installations provide a means to examine personal beliefs, interests and values.

Asking project members to reflect on their own experiences and produce and share something to reflect personal interests meant that this project was rooted in personal goals and aspirations. This work was, therefore, based upon questions about what individuals care about and want to achieve. This mean that the eventual form of the project emerged from the specific interests of members. However, whilst a good starting point we do not believe that action research should be a solely individual affair (McNiff, 2012) and so:

(2) Arts installations provided a shared experience which could generate common understandings and result in the development of shared values amongst project members.

The second feature of this arts installation approach to reconnaissance builds on the reflective consideration of personal interests. Individual members of the team come to understand each other better by describing the items that they produced and then explaining their significance to them. But the group starts to form closer alliances and develop common interests by reviewing these items, grouping them and starting to draw out themes which have implications for actions. This provides a productive way to understand, embrace and work with a diversity of views and values and to allow order, in the form of shared understandings, common values, productive relationships, and negotiated activities, to emerge from a 
complex (Ahmadian and Tavakoli 2011) but productive 'mess' (Cook, 2009) of differing experiences and aspirations. The arts installations therefore moved beyond the reflective interpretation of reconnaissance (Robertson, 2000; Webb \& Scoular, 2011) to establish a social process through which shared values could be established to provide the subsequent basis for collective and individual actions.

(3) The adoption of arts installations was geared towards creative production and was associated with inquisitiveness and possibility rather than guilt and despair.

This challenged an ontological position on water education underpinned with messages of remorse over the mismanagement of natural resources, and instead stimulated a dialogue of possibilities for understand and changing this situation. This is congruent with Bishop's (2005) notion of 'activated spectatorship' discussed earlier.

\section{Reconsidering reconnaissance, arts installations and creative, collective, problematisation}

Through the use of a creative provocation based in artistic practice, we believe we achieved a reinterpretation of reconnaissance as a stage of action research less concerned with establishing the facts of a given situation, or with collecting data to baseline change, and more intended to provide an open ended and not-knowing creative stimulus to understand and build upon shared aspirations and values. This provides one way to make sense of complexity (Davis \& Sumara, 2005; Mayer, 2003; Phelps \& Hase, 2002) and productively to utilise the 'mess' of a variety of interests, experiences and values (Cook, 2009) in a collective action research project involving multiple partners. It also provides an alternative to the representation of action research as a logical predictable sequence commonplace in education in England at present. 
Our proposal is to treat the early stages of action research as a way creatively to examine the aspirations of action researchers, to challenge their preconceptions and to embark on a shared activity which allows relationships to be formed between collaborators. This provides a means to recognise and honour individual interests, and to use these as a starting point from which to establish shared values to underpin collective endeavour. The early stages of action research are, therefore, conceived of as a period of problematisation and relationship formation. We are not suggesting that the use of arts installations is the only way to achieve this. We are however hoping that this one example might stimulate further conversation, disrupt the utilitarian approaches to action research that are currently in vogue, at the same time as assisting in the development of a new repertoire of reconnaissance practices.

Postscript: Readers may be curious about the remainder of these projects, what actions they promoted and the learning they supported. These are presented on the project website (www.getwet.org.uk)

References:

Adleman, C. (1993). Kurt Lewin and the Origins of Action Research. Educational Action Research, 1(1), 7-24.

Ahmadian, M. J., \& Tavakoli, M. (2011). Exploring the utility of action research to investigate second-language classrooms as complex systems. Educational Action Research, 19(2), 121-136

Bana, Z. (2010). 'Great Conversation' for school improvement in disadvantageous rural contexts: a participatory case study. Educational Action Research, 18(2), 213-237.

Bishop, C. (2005) Installation Art. London: Routledge.

Burns, D. (2007). Systemic Action Research: a Strategy for Whole System Change. Bristol: The Policy Press.

Cain, T., \& Harris, R. (2013). Teachers' action research in a culture of performativity. Educational Action Research, 21(3), 343-358. 
Carr, W., \& Kemmis, S. (1986). Becoming Critical, Education, Knowledge and Action Research. London: Routledge.

Coldron, J., Crawford, M., Jones, S., \& Simkins, T. (2014). The restructuring of schooling in England: The responses of well-positioned headteachers. Educational Management Administration \& Leadership, 42(3), 387-403.

Cook, T. (2009). The purpose of mess in action research: building rigour though a messy turn. Educational Action Research 17(2): 277-91

Cordingley, P., \& Groll, A. (2014). Teacher Enquiry is the Key to Learning. Coventry: CUREE.

Davis, B., \& Sumara, D. (2005). Complexity science and educational action research. Educational Action Research, 13(3), 453-464.

Elsey, H., \& Lathlean, J. (2006). Using action research to stimulate organisational change within health services: experiences from two community based studies. Educational Action Research, 14(2), 171-186.

Godfrey, D. (2014). Leadership of schools as research-led organisations in the English educational environment: cultivating a research-engaged school culture. Educational Management Administration \& Leadership.

Grundy, S. (1987). Curriculum: Product or Praxis. London: The Falmer Press.

Hadfield, M., \& Bennett, S. (1995). The Action Researcher as Chameleon. Educational Action Research, 3(3), 323-335.

Hunt, B. J. (2010). Pursuing Power and Light : Technology and Physics from James Watt to Albert Einstein. Baltimore, MD, USA: Johns Hopkins University Press.

Jones, R. (2013). On the value of now knowing. Wonder, beginning again and letting be. In E. Fisher \& R. Fortnum (Eds.), On not knowing. How artists think. London: Black Dog Publishing.

Kemmis, S. (2010). What is to be done? The place of action research. Educational action research, 18(4), 417-427.

Kollmuss, A., \& Agyeman, J. (2002). Mind the Gap: Why do people act environmentally and what are the barriers to pro-environmental behavior? Environmental Education Research, 8(3), 239-260.

Lewin, K. (1946). Action Research and Minority Problems. Journal of Social Issues, 2(4), 34-46.

Lewin, K. (1947). Frontiers in group Dynamics: II. Channels of Group Life; Social Planning and action research. Human Relations, 1(2), 143-153.

Mason, R. (2005). Art teachers and action research. Educational Action Research, 13(4), 563580. 
Mayer, M. (2003). Living at the Border: between multiculturality, complexity and action research, Educational Action Research, 11(2), 213-232

McNiff, J. (2012). Travels around identity: transforming cultures of learned colonisation. Educational Action Research 20(1): 129-46

McNiff, J. (2013). Action Research: Principles and Practice. London: Routledge.

NCTL. (2014). Impact of Teaching Schools. Nottingham: National College for Teaching and Leadership.

Nicol, R. (2013). Fostering environmental action through outdoor education. Educational Action Research, 22(1), 39-56.

Noffke, S. (2009). Revisiting the Professional, Personal, and Political Dimensions of Action Research In S. Noffke \& B. Somekh (Eds.), The Sage Handbook of Educational Action Research. London: Sage.

Phelps, R. \& Hase, S. (2002). Complexity and action research: exploring the theoretical and methodological connections. Educational Action Research, 10(3), 507-524,

Reiss, J. (1999). From margin to center: the spaces of installatioin art. Cambridge MA: The MIT Press.

Robertson, J. (2000). The three Rs of action research methodology: reciprocity, reflexivity and reflection-on-reality. Educational action research, 8(2), 307-326.

Rué, J. (2006). Reconstructing teaching professionalism in the new modernity: an agenda for new action narratives 1. Educational Action Research, 14(1), 119-138.

Thomson, P., Hall, C., Jones, K., \& Sefton Green, J. (2012). Signature pedagogies. London: Creativity, Culture and Education. Also available on http://www.artsandcreativityresearch.org.uk.

Tragoulia, E., \& Strogilos, V. (2013). Using dialogue as a means to promote collaborative and inclusive practices. Educational Action Research, 21(4), 485-505.

Webb, L. A., \& Scoular, T. (2011). Reflection on reflection on reflection: collaboration in action research. Educational Action Research, 19(4), 469-487.

Winter, R. (1998). Finding a voice - thinking with others: a conception of action research. Educational action research, 6(1), 53-68.

Wood, L. (2012). Action Research: Its Trasnformative Potential. Educational Research for Social Change 1(1): 1-4 